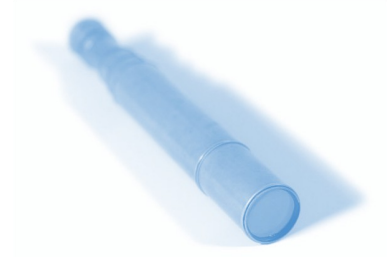

\author{
Jo Tunney \\ Royal Society of Chemistry \\ Burlington House \\ Piccadilly \\ London \\ W1J 0BA
}

\title{
A legacy for chemistry education
}

\begin{abstract}
The Royal Society of Chemistry (RSC) has a longstanding reputation for providing innovative and up to date support for chemical science education - from primary, through to higher education and beyond. The RSC is continually developing easily accessible resources and events to help meet the needs of changing curricula and the skills required by employers.
\end{abstract}

At A-level and degree level the focus is on increasing the numbers of students studying chemistry and the chemical sciences in order to educate the next generation of sciencebased professionals. The Chemistry for our Future (CFOF) programme was established with the aim of ensuring a strong and sustainable future for chemical sciences in higher education by increasing the aspirations of students, promoting the chemical sciences at all levels and improving the school to university transition.

\section{The background}

Chemistry for our Future was funded by the Higher Education Funding Council for England (HEFCE) and managed by the RSC. The initiative began on $1^{\text {st }}$ September 2006 with initial funding of $£ 3.6 \mathrm{~m}$. A further $£ 1.65 \mathrm{~m}$ was secured to extend CFOF until July 2009. The programme involved over 35 separate projects and 30 higher education institutions, covering four main areas:

- Chemistry: The Next Generation (CTNG)

- Teacher and academic fellowship scheme

- Higher education curriculum development

- Widening access to university laboratory facilities

Two cross cutting themes addressed the provision of career information and the sharing of good practice.

\section{Future generations}

Chemistry: The Next Generation (CTNG) was an outreach project that aimed to raise aspirations and engage with students from backgrounds that do not traditionally participate in higher education. The project operated in six English regions - the South East, London, North East, Yorkshire and Humber, East Midlands and North West - and its strength lay in the range of collaborative events that enhanced and enriched the curriculum and met the needs of local schools and colleges. The programme was managed centrally by the RSC and was run 'on the ground' by Regional Coordinators who worked closely with the higher education institutions in their region as well as other outreach providers. Over 60,000 students have been involved in outreach events since September 2006.

These events have provided a new cohort of students with first-hand experience of the chemical sciences in action, including activities such as Murder in the lab - where the students used forensic techniques to investigate a 'murder'; Aspirin, the wonder drug; Make your own electrochromic polymer; Renewable energy from sunlight to electricity and Building molecules. For information on these and other activities visit the RSC website at www.rsc.org/Education/CFOF

\section{Bridging the gap}

For many students the transition from school to university is not always smooth and CFOF has tackled this through a range of new initiatives, including chemistry 'boot camps' and on-line maths resources, aimed at boosting students' confidence, learning and practical mathematical skills. 
Nine secondary school teachers have also spent up to two years working in their local university, to work on a range of enrichment projects as part of the teacher and academic fellowship scheme. The Teacher Fellows undertook work to:

- improve understanding in universities of A-level chemistry and GCSE science courses, current practices in schools and colleges, and the capabilities of incoming undergraduates;

- raise awareness amongst teachers, students, parents and guardians of what it is like to study chemistry at university, the benefits of higher education and the career options available to chemical science graduates; and

- develop sustainable links between universities and schools and colleges.

One teacher fellow described what the scheme provided for them; 'When I return to school I am in no doubt it will be as a more effective and enthusiastic teacher. This really is a great job'.

The teachers have worked at the universities of Sheffield, Nottingham, Birmingham, Warwick, Bath, Leeds, Newcastle, Northumbria and University College London on a variety of projects. These have included developing new curriculumbased outreach activities, undertaking evaluations of first year teaching and developing an Interactive Lab Primer (ILP), which is a visual guide to common laboratory techniques (www.rsc-teacher-fellows.net/index.htm). The aim of the ILP is to address the diverse range of experience and practical skills that students bring with them to university by providing extra support in developing practical techniques, familiarisation with new pieces of equipment and information on working safely.

Ten university-based pilot projects have also been developed, focussing on improving the school-to-university transition. Together, they address the key areas of maths and practical skills, new teaching materials and student support schemes: www.rsc.org/Education/CFOF

The projects have concentrated on a wide range of activities to help students overcome the sometimes difficult transition from school to university. This has included developing on-line resources to cover the essential mathematical principles that chemists need to apply and also reviewing how maths is taught to undergraduates. Practical skills have also been honed through pre-induction courses and knowledge gaps have been addressed by using short on-line video clips focused on 'bite sized' learning objectives. These projects have achieved much in a short period of time and hopefully they will continue to evolve and provide further benefit for students and those teaching and supporting them.

\section{Developing HE curricula}

Chemistry for our Future provided a unique and timely opportunity to review existing chemical science degree courses to ensure that courses appeal to prospective students from all backgrounds and deliver the skills required by employers in the chemical, pharmaceutical and other industries.
The higher education curriculum development strand of CFOF was grouped into the following themes:

- developing Context- and Problem-Based Learning;

- developing an open learning framework; and addressing the challenges of the Bologna process.

\section{Chemistry for all - alternative approaches to chemistry curricula}

The focus of this project was to provide a data set for evaluating the effectiveness of Context-Based Learning (CBL) and Problem-Based Learning (PBL) in chemistry curricula. The project was carried out by the universities of Leicester, Hull, Nottingham Trent and Plymouth and had the following aims:

- To implement existing CBL/PBL materials into undergraduate chemistry courses at four English universities.

- To measure the effects of these alternative approaches with different student groups (e.g. full time, part time, foundation degree students and distance learners) in terms of student performance, student satisfaction and engagement, staff perception and resource implications.

- To investigate the transferability of existing CBL/PBL materials to institutions other than those where they were initially developed.

- To survey materials being used in other institutions.

- To share good practice, ideas, materials and innovations and provide rational cross-discipline planning in collaboration with the parallel HEFCE funded, Institute of Physics managed project, Stimulating Physics.

- To identify new areas for future development.

- To develop new resources tailored for the delivery of CBL/PBL approaches.

\section{Mastering Bologna}

With 2010 fast approaching, the Bologna process is a pressing issue for HE. In chemistry and the chemical sciences there are areas of the process that will potentially have a huge effect on both students and HEls. The aim of this project was to gather data and opinion on the readiness of the UK chemistry HE sector to succeed after the introduction of the European Higher Education Area (EHEA). The Bologna Agreement defines a route to a pan-European structure for higher education provision, which in practice could mean three year BSc degrees followed by two year Masters and then three year PhDs.

The Mastering Bologna report was launched in December 2008 and the findings and recommendations show there is still a lot of work to be done before the Bologna Agreement comes into effect in 2010.

The Bologna Agreement will introduce three main cycles of higher education qualifications; a three year Bachelors followed by a two year Masters and a three year $\mathrm{PhD}$. This model will be adopted by universities across Europe to allow for greater international mobility between member states (EU and non-EU) for study and employment through mutual recognition of $\mathrm{HE}$ qualifications. 
While many countries in the EU already fit this model, the UK falls short at the second cycle where the common duration for a Masters is only one year. The chemistry HE sector faces a further obstacle with the highly popular integrated Masters qualification - e.g. MSci and MChem, which removes the second cycle altogether.

The report findings show that it is unlikely the integrated four year Masters will be acknowledged internationally as equivalent to a combined first and second cycle qualification in the EHEA ${ }^{1}$. With approximately $40 \%$ of UK chemistry graduates qualifying with this degree, this poses a huge threat to UK graduates competing for employment, both domestically and internationally. Should the MChem and MSci degrees lose their reputation for providing graduates with good employment prospects their popularity with overseas students will also decline. This ultimately will have negative consequences for the sustainability of a number of UK chemistry departments'.

\section{Smarter use of laboratories}

In recent years chemistry, amongst other science subjects, has suffered from a reduction in the number of applications for degree courses. Whilst the latest UCAS data shows that acceptances to chemistry are at a 10 year high there is clearly much more work that needs to be done to sustain this increase in applications. This can be tackled, in part, by improving young peoples' perception of science and by promoting and facilitating sound scientific understanding and training. Research shows that there is a need to make science more engaging in the classroom through practical experiments. Hands-on work helps to make science compelling for young people. However, a lack of good laboratory facilities and equipment in many schools and colleges makes this difficult.

Chemistry for our Future has worked with the Bristol ChemLabs CETL and the University of Sheffield to explore ways of making better use of university laboratories to benefit students in secondary schools and colleges. These projects gave school and college students a taste of what it is like to study chemistry at university. Activities included introductory sessions for Year 11 students, GCSE revision workshops and a suite of curriculum based experiments.

These initiatives support science teaching for Year 5 to Year 12 students and their teachers, by providing access to good quality practical facilities. This gives students the opportunity to do

- two academic years of Masters level education should be made widely available in the UK although the current four academic year integrated Masters degrees are to remain for the foreseeable future;

- the nomenclature of UK science degree programmes needs to be rationalised to avoid confusion outside the UK;

- higher education institutions should continue to strengthen links with industry in the direct provision of student learning opportunities;

- HEFCE and the Research Councils need to agree financial responsibilities for Masters degrees and make sustainable new provision for Masters level education; and

- HEFCE and the Research Councils need to consider new funding for scholarships for UK students undertaking Masters courses.

The full report is available on the RSC website at: http://www.rsc.org/images/MasterBologna_tcm18-159351.pdf experiments they may not

\begin{abstract}
be able to do in their classroom and encourages them to
\end{abstract} consider continuing to study science. By giving the students the chance to use the schools laboratories on more than one occasion, they experience a sustained engagement with higher education rather than a more limited 'one-off hit'.

As one student says; 'The day gave me an insight into working in a laboratory and has inspired me to choose a course at university with a biology and chemistry base'.

The teachers also enthused about the facilities; 'The students were unanimous in their responses about their experience. They all said how much they had enjoyed the day. They felt they learnt some good and relevant chemistry and also felt that the practical exercise was very worthwhile. They have even asked if they can go again next term'.

Another initiative promoting laboratory techniques is Spectroscopy in a Suitcase (SIAS), which brings the take cutting-edge spectroscopy equipment into classrooms across England to give students practical experience of the theoretical techniques they are learning about. laboratory to schools and colleges. Postgraduate students 
Spectroscopy resource packs have been designed to compliment the SIAS workshops but are equally valuable as stand alone resources. Each pack contains a range of activities on infrared spectroscopy, UV-visible spectroscopy and mass spectrometry. In one instance, students work through a murder investigation and have to discover the cause of death with the aid of infrared spectroscopy. Other activities include screening for aspirin overdose and studying food dyes using UV. By relating the techniques to real investigative activities students can see for themselves why spectroscopy is such a vital tool in analysis.

Chemistry for our Future has also developed free online resources to support spectroscopy teaching in schools and colleges (www.rsc.org/Education/CFOF). SpectraSchool was re-launched in January 2009 at the Association of Science Education (ASE) conference and provides real, interactive spectra of IR, NMR, UV-Vis and MS for a large library of compounds. Students (and teachers) can study and compare spectra by zooming and overlaying compounds and there is also the opportunity to watch video clips illustrating the practical aspects of the techniques. These extra resources will really help maximise the impact throughout the country.

\section{Other themes}

There are many exciting career opportunities available with a chemical science qualification and CFOF has worked to provide students with the most up to date information. New resources were developed in collaboration with chemical science employers and events were run that gave students and careers advisers the chance to meet real scientists and find out what it's like to work in a particular field.

Chemistry for our Future worked closely with schools, colleges, industry and $\mathrm{HE}$ around the country promoting chemical sciences as a stimulating and profitable career. This led to a wide range of activities targeting students from primary school level to A-level, and with a particular emphasis on widening participation.

A series of careers fairs in Birmingham, Norwich and Paignton was developed as part of the programme to give students the chance to meet employers, listen to presentations and take part in hands-on activities. Two careers conferences were also held to inform teachers and career advisors of the career opportunities available in the chemical sciences, through a series of workshops, presentations and exhibitions.

A major aspect of CFOF has been the collection of baseline information and evaluation of activities. One specific project in this area has been research to examine the fit between the supply and demand of chemical science graduates in the UK. The work was undertaken by the Warwick Institute for
Employment Research, looking at the employment perceptions, attitudes and experiences of chemical science students and graduates at different stages of their career development. General graduate and specialist chemical science employers were asked questions about their experiences of recruiting chemical science graduates, the types of jobs they do within their organisation and their perception of the skills chemical science graduates possess.

The study provided a wealth of information with some of the key findings listed below.

- Students reported a high degree of satisfaction with their chemical science courses and with the HE experience in general.

- A third of final year students said that they broadly knew what they wanted to do and how to do it, with $45 \%$ seeking careers advice in the previous two years.

- Work that was challenging and interesting was the most important thing that students looked for when considering suitable jobs.

- General graduate employers stated that they were unlikely to favour MChem graduates over BSc graduates and were more interested in transferable skills. However, specialist chemical science employers did distinguish between the two, with higher degrees particularly sought after for research or academic positions.

- The majority of chemical science employers said that they had no problems filling vacancies and they are satisfied with the number of applications.

- Employers felt that skills such as physical chemistry, physical organic chemistry, analytical science and the ability to work on large scale research projects were in short supply.

- Written and spoken communication skills and business awareness were the most common transferable skills that employers felt chemical science graduates lacked.

- Students felt that more could be done to provide them with information about the kinds of careers available and were critical of information they received from employers and professional bodies, stating that it was not detailed enough.

- Employers expressed the concern that chemical science graduates are not aware of the range of options available to them and as a result were less likely to consider areas with good opportunities such as manufacturing and technical sales.

A short digest and the full version of the report are available at www.rsc.org/Education/CFOF. 


\section{The legacy}

Chemistry for our Future has established many successful activities that have scope for further development to continue to have a major influence on the experience of students in schools, colleges and HEls. The main legacy of the programme has been establishing successful working partnerships with a range of stakeholders, including students, school teachers, university lecturers, industry and other professional bodies. Outreach activities such as Spectroscopy in a Suitcase which are delivered in the classroom will be extended and continue to develop, and the RSC is looking at sustainable ways of continuing the work of the network of regional coordinators.

Several major strands will provide a lasting legacy from the project:

- Universities that have benefited from teacher fellows have started to restructure their degree programmes to better meet the needs of future students.

- New tools have been developed to support students as they settle into university life, these will be rolled out in more universities.

- Networks of HEl staff and teachers with an interest in developing teaching and learning have been established.

- The profile of widening participation has been raised in the chemistry community.

- Future students will benefit from the newly refurbished school laboratory facilities at the University of Sheffield.

- SpectraSchool, a library of spectral data, interactive tools and spectroscopic teaching resources, will continue to be developed and promoted to students and teachers.

- A series of new CBL/PBL resources that are available 'off the shelf' have been developed.

- A better understanding of issues surrounding the Bologna process has emerged, which the RSC will take forward with funding agencies and other professional bodies.

- A framework for an effective national outreach scheme has been established.

\section{The future}

The Higher Education Funding Council for England (HEFCE) announced earlier in the year that the University of

Birmingham will host the national Higher Education Science Technology Engineering and Maths (STEM) programme for a period of three years from August 2009. The integrated STEM programme will have a potential budget of $£ 20 \mathrm{~m}$ and will build on the successes of the four current HEFCE funded STEM demand-raising projects; Chemistry for our Future, Stimulating Physics, More Maths Grads and the London Engineering Project. The aim of the programme is to deliver a sustained increase in STEM graduates, meeting the needs of employers and satisfying the demand for higher-level skills in STEM subjects.

\section{References}

1. Mastering Bologna: A Report on the Readiness of UK

Chemistry Departments to Succeed in the European Higher

Education Area, Chemistry for our Future, Royal Society of

Chemistry, 2009

<www.rsc.org/images/MasterBologna_tcm18-159351.pdf>
The main legacy of the programme has been establishing successful working partnerships with a range of stakeholders, including students, school teachers, university lecturers, industry and other professional bodies. 